\section{FDG-PET of poststroke oculomotor repair}

D.S. Liebeskind, MD, B.M. Ances, MD, A.B. Newberg, MD, D.A. Jacobs, MD, A. Alavi, MD, Philadelphia, PA

A 35-year-old woman with congenital heart disease status post surgical repair presented in coma due to a top of the basilar syndrome. Neuro-ophthalmologic examination disclosed a dorsal midbrain syndrome. FDG-PET revealed minimal uptake of tracer in the extraocular muscles 1 week from stroke onset (figure 1), with a

Address correspondence and reprint requests to Dr. David S. Liebeskind, Comprehensive Stroke Center and Department of Neurology, University of Pennsylvania, 3 West Gates Building, 3400 Spruce Street, Philadelphia, PA 19104-4283; e-mail: davidliebeskind@yahoo.com

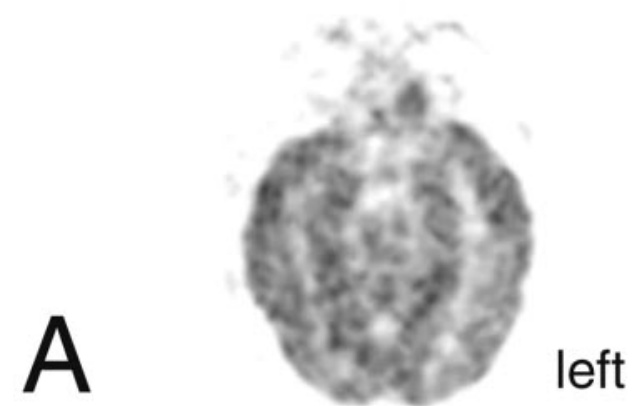

left
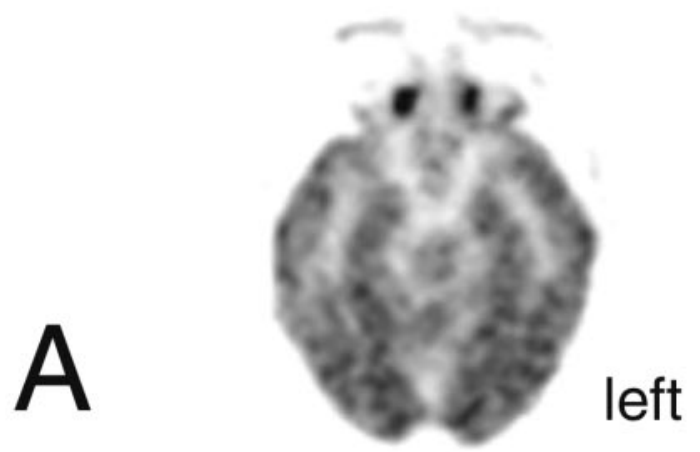

Law I, Svarer C, Rostrup E, Paulson OB. Parieto-occipital cortex activation during self-generated eye movements in the dark. Brain 1998;121: $2189-2200$.

dramatic increase in FDG uptake in the extraocular muscles noted at 1 month (figure 2). Concurrent intensification of FDG uptake in the extraocular muscles and bilateral parieto-occipital cortices correlated with improvement in her gaze paresis. Although extraocular muscle tracer uptake has been characterized as an artifact, this unique case illustrates poststroke oculomotor recovery. ${ }^{1}$
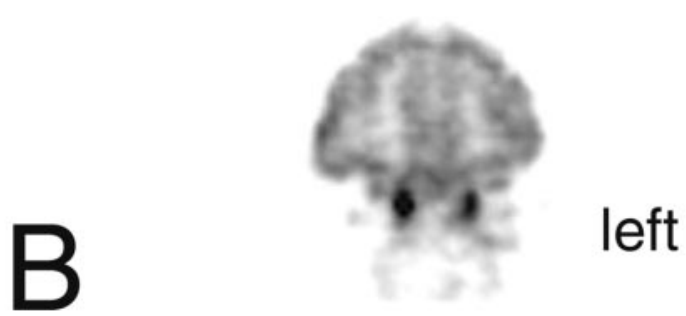

left
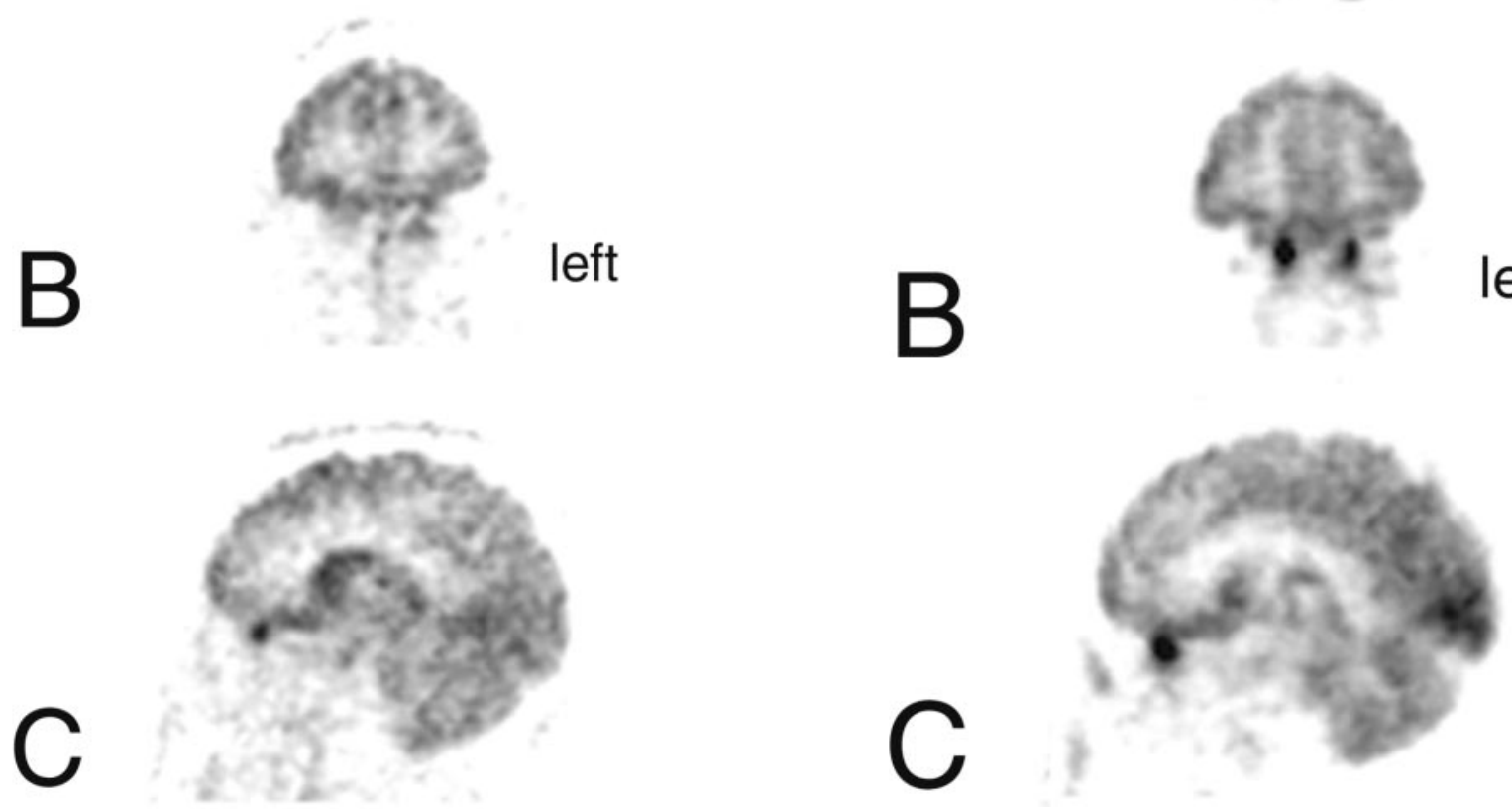

Figure 1. FDG-PET demonstration of minimal extraocular muscle tracer uptake at 1 week from stroke onset (A, axial; B, coronal; $C$, left parasagittal).

Figure 2. FDG-PET at 1 month from stroke onset (A, axial; $B$, coronal; $C$, left parasagittal) demonstrates marked extraocular mus cle tracer uptake and increased uptake in the parieto-occipital cortex. 